\title{
Structural characteristics determine productivity in complex cocoa agroforestry systems
}

\author{
Patrick Jagoret $^{1}$ (D) Isabelle Michel $^{2} \cdot$ Hervé Todem Ngnogué $^{3} \cdot$ Philippe Lachenaud $^{4}$. \\ Didier Snoeck $^{5}$ - Eric Malézieux ${ }^{6}$
}

Accepted: 13 October 2017 /Published online: 9 November 2017

(C) The Author(s) 2017. This article is an open access publication

\begin{abstract}
In order to cope with current challenges facing world cocoa production and the obvious lack of sustainability of the intensive model proposed to farmers, more ecologically efficient cocoa cropping systems must be developed, based in particular on a higher cultivated biodiversity level. The performances of cocoa multispecies systems, which involve multiple and hard to quantify interactions, are, however, more complicated to assess than that of monospecies systems. Despite this hurdle, we carried out a study in 48 cocoa agroforests located in three zones in central Cameroon where we conducted an analysis of cocoa yield components and agroforestry system structural characteristics that are likely responsible for observed yield variations. For the first time, we adapted the regional agronomic diagnosis method to demonstrate that the basal area per cocoa tree (mean $61.6 \mathrm{~cm}^{2}$ ) and the unproductive adult cocoa tree rate (mean 21\%) are key factors when assessing the productive performance of the surveyed systems whose average cocoa yield was $737 \mathrm{~kg} \mathrm{ha}^{-1}$. From a methodological standpoint, the assessment approach we set up succeeded to overcome the specific obstacles linked with the features of
\end{abstract}

Patrick Jagoret

patrick.jagoret@cirad.fr

CIRAD, UMR SYSTEM, F-34398 Montpellier, France

2 IRC-Montpellier SupAgro, UMR Innovation, F-34398 Montpellier, France

3 IRAD-Nkolbisson, BP 2572 Yaoundé, Cameroon

4 CIRAD, UPR Pests and Diseases: Risk Analysis and Control, F-34398 Montpellier, France

5 CIRAD, UPR Performance of Tree Crop-Based Systems, F-34398 Montpellier, France

6 CIRAD, UPR HortSys, F-34398 Montpellier, France agroforestry systems, especially their complexity (number of species and heterogeneity), by (i) determining relevant indicators and easily measurable variables, (ii) considering the associated tree communities as an environmental component, and (iii) analyzing interactions between cocoa stands and associated tree communities. From an operational standpoint, we showed that farmers can intervene on the structural characteristics of their cocoa agroforests to improve cocoa yields, in particular by eliminating unproductive cocoa trees whose basal area is less than $19 \mathrm{~cm}^{2}$ to enable the other ones to grow.

Keywords Regional agronomic diagnosis $\cdot$ Yield components · Yield-limiting factors · Yield variability · Theobroma cacao L. · Tree community · Cocoa trees · Cameroon

\section{Introduction}

In recent decades, agricultural development has mainly involved chemical intensification and extreme simplification of cropping systems, with most species being cropped in pure stands. Such intensive agroecosystems are now increasingly questioned because of their negative environmental impacts (Tilman et al. 2002). In both tropical and temperate areas, the challenge is to develop more sustainable and ecologically efficient cropping systems, among others by promoting cultivated biodiversity (Altieri and Rosset 1995; Malézieux et al. 2008). Different "ecologically intensive" model design frameworks have thus been proposed (Malézieux 2012; Gaba et al. 2015). However, existing multispecies systems - from which agronomists could be inspired - are much harder to assess than monospecies systems because of their inherent heterogeneity, hence the many difficulties to quantify interactions (Doré et al. 2008; Malézieux et al. 2008). This is the case especially for 
complex agroforestry systems in the humid tropics that have many potential advantages that could be tapped depending on the relationships and regulations between species in the agrosystem, i.e., a higher overall productivity per unit area, a better control of pest pressure, and increased environmental services such as biodiversity conservation, soil fertility, and carbon sequestration (Malézieux et al. 2008). The complexity of such agrosystems and the different objectives they address make it hard to evaluate their productivity and identify factors limiting yields of the main crop (Malézieux et al. 2008).

Cocoa agroforestry systems are of particular interest in this setting. World cocoa production reached 4.3 million $\mathrm{t}$ in 2015 of which three quarters come from four African countries: Côte d'Ivoire, Ghana, Nigeria, and Cameroon (ICCO 2016). Meanwhile, the global cocoa orchard covers a 10 million-ha area, and it is characterized by yield differences between plantations, ranging from 80 to $4000 \mathrm{~kg} \mathrm{ha}^{-1}$, depending on farmers' practices and cropping systems (Rafflegeau et al. 2014). Cocoa cropping is indeed generally based on two different technical approaches: (i) an intensive model that promotes the use of selected varieties managed without shade or under homogeneous light shade, with high chemical fertilizer and pesticide inputs (Wood and Lass 2001), and (ii) agroforestry systems which represent 50 to $60 \%$ of the world cocoa orchard and where cocoa trees are associated with other multipurpose forest or fruit trees (Clough et al. 2009). The associated trees provide shade to the cocoa trees, and many products to farmers (fruit, wood, leaves, medicinal barks, etc.), whether marketed or not, which contribute to the self-sufficiency and the economic equilibrium of the households (Cerda et al. 2014; Jagoret et al. 2014a).

Although the intensive model has reached its limits in terms of sustainability, thereby indicating that serious thought must be given to improve it by developing new cocoa cropping systems (Jagoret et al. 2014b), little is currently known about the functioning of complex cocoa agroforestry systems. Three main reasons can explain the little interest on agroforestry systems: first, based on the assumption that shade limits the productivity of cocoa trees (Wood and Lass 2001), cocoa agroforestry systems have generally been overlooked by researchers due to their presumed low cocoa yields. Second, almost all benchmark of cocoa cropping systems were designed on the basis of studies which were conducted mainly in research stations over the 1950-1980 periods and were geared towards optimizing cocoa tree productivity in relatively undiversified systems. Third, assessing the specific yield of a given species in a multispecies system is hard because it involves taking explicitly into account the other cultivated species in the system, their place, and role (Malézieux et al. 2008). This is particularly the case in central Cameroon where most of the cocoa orchard is agroforestry based (Sonwa et al. 2007; Jagoret et al. 2011, 2012) (Fig. 1) and presents a great intra-plot cocoa yield variation (Jagoret et al. 2008), while factors cannot be accurately determined. However, these agroforestry systems can be a potential source of inspiration for designing new ecologically intensive cocoa cropping models.

In order to overcome this lack of knowledge, we carried a study that involved an analysis of cocoa yield components in agroforests located in three zones of central Cameroon. The structure of the agroforestry system (e.g., cocoa trees and associated trees density and basal area, type of associated tree species) was considered as a major factor to explain cocoa yields. The main causes of yield variations observed in a range of cocoa agroforests located in three areas were identified and classified to assess the diversity of cases on a regional scale. Finally, the analysis of yield variation was done using the regional agronomic diagnosis method developed by Doré et al. 1997; 2008) that we implemented and adapted to cocoa agroforestry systems.

\section{Materials and methods}

\subsection{Regional agronomic diagnosis methodology}

This method, proposed by Doré et al. 1997; 2008), allows understanding, for a crop, the yield variations, highlighting

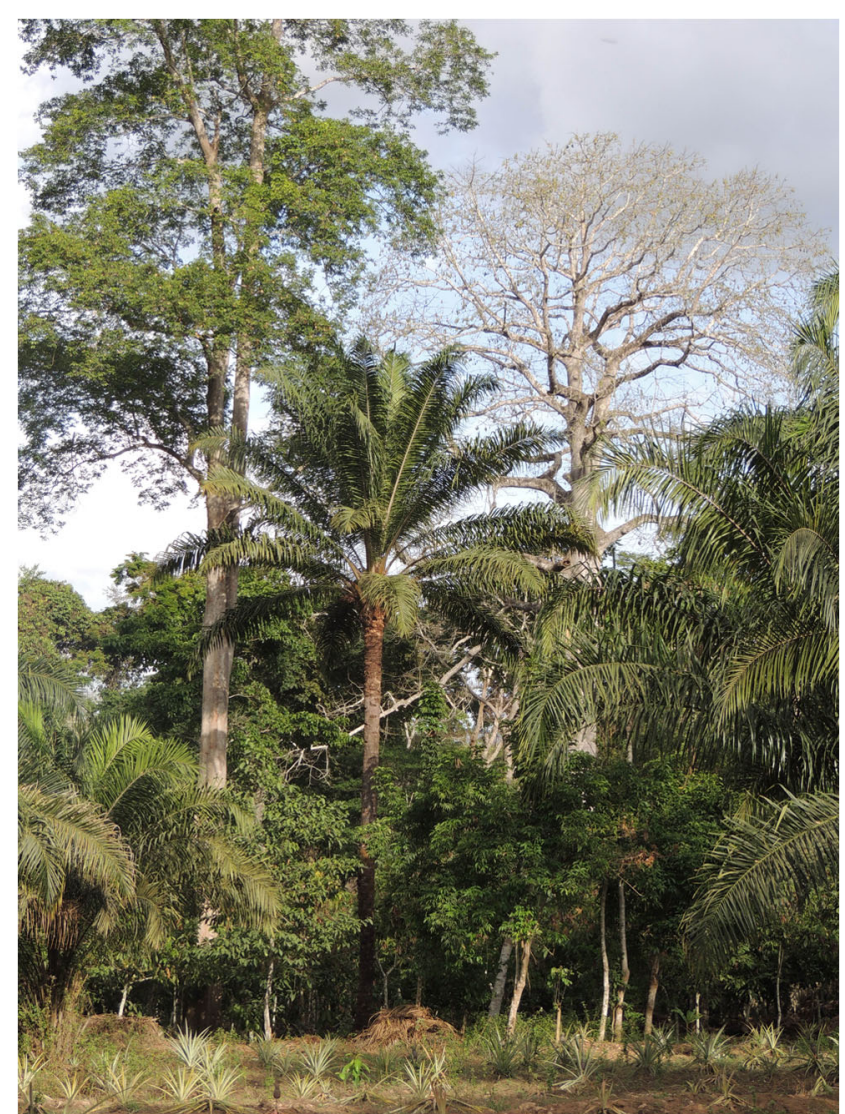

Fig. 1 Typical cocoa agroforest in Central Cameroon. One can distinguish the three main strata that make up the agroforestry system: the cocoa stratum dominated by an intermediate stratum composed mainly of fruit trees, all dominated by a high stratum of forest trees 
environmental factors and farmers' practices responsible for the low yields. It is based on a conceptual model of crop yield build-up, linking the status of the cultivated stand to the environmental status and farmers' practices. The regional agronomic diagnosis was mainly used to assess homogeneous systems in terms of composition and structure, often with only one component, usually one annual species (Scopel and Louette 1992; Leterme et al. 1994; Metral and Wery 2001). In Cameroon, Michels (2005) and Rafflegeau et al. (2010) adapted this method to the case of perennial crops to identify limiting factors for the performance of homogeneous stands of rubber trees and oil palm. In the case of complex cocoa agroforestry systems, to overcome the difficulties related to their specific features, particularly their complexity and heterogeneity, we assumed that the key factor to explain cocoa yield variability was the structural characteristics of these systems, i.e., density and basal area of cocoa trees and associated trees, type of associated trees (forest or fruit trees), height and number of trunks of cocoa trees, which are the result of farmers' practices. Farmers intervene on the different stands, i.e., by cutting back and replanting for cocoa stands, or by managing the associated trees (choice of species, elimination of trees, etc.) (Jagoret et al. 2017). Unlike monospecific cropping systems based on annual species where the environmental status is usually characterized by soil and climate, many interactions (facilitation or competition) occur between species in complex agroforestry systems (Malézieux et al. 2008). As the availability of water, soil nutrients, and light depends on the relationship between the cocoa trees and the associated species, we therefore considered the associated species as a variable similar to the environmental status. As a matter of fact, the structural characteristics of agroforestry systems allowed us to carry out a regional agronomic diagnosis, like Rafflegeau et al. (2010) did one to assess the nutritional status of palm oil smallholdings.

\subsection{Study sites}

Our study was carried out in a specific study network in central Cameroon located in three different cocoa growing zones: Bokito ( $\left.4^{\circ} 35^{\prime} \mathrm{N} ; 11^{\circ} 8^{\prime} \mathrm{E}\right)$, Zima $\left(4^{\circ} 7^{\prime} \mathrm{N} ; 11^{\circ} 25^{\prime} \mathrm{E}\right)$ and Ngomedzap $\left(3^{\circ} 16^{\prime} \mathrm{N} ; 11^{\circ} 14^{\prime} \mathrm{E}\right)$, representative of (i) the north-south gradient of natural conditions in this region (Santoir and Bopda 1995) and (ii) the local cocoa cropping systems in terms of structural characteristics (Jagoret et al. 2011). Central Cameroon encompasses an area located between $2.1^{\circ}$ to $5.8^{\circ} \mathrm{N}$ and $10.5^{\circ}$ to $16.2^{\circ} \mathrm{E}$, with a 600 $800 \mathrm{~m}$ elevation range. The climate is hot and humid, with an average annual temperature of $25^{\circ} \mathrm{C}$. There are two distinct wet and dry seasons that vary in duration from north to south (bimodal rainfall regime). The average total annual rainfall is around $1400 \mathrm{~mm}$ in Bokito, $1600 \mathrm{~mm}$ in Zima, and $1800 \mathrm{~mm}$ in Ngomedzap. The main dry season lasts 5 months in Bokito (mid-November to mid-April) and 3 months in Zima and Ngomedzap (mid-November to mid-February). Bokito is located in the forest-savannah transition zone where there is low land pressure ( 29 inhab $\mathrm{km}^{-2}$ ). It is characterized by a patchwork of forest galleries and herbaceous and sedge savannahs on rejuvenated slightly desaturated soils. Zima is located in a forest zone with considerable human activity (111 inhab $\mathrm{km}^{-2}$ ), where the vegetation pattern is influenced by forest clearing and tree cropping on moderately desaturated ferrallitic soils. Finally, Ngomedzap is located in the forest zone where there is low land pressure ( 37 inhab km$~^{-2}$ ), and the prevailing vegetation is a dense evergreen forest on highly desaturated ferrallitic soils (Santoir and Bopda 1995).

\subsection{Experimental design}

A network of 48 productive cocoa agroforests (plot age range 11-77 years) was set up in the three areas in 2007 and monitored from 2008 to 2009 (Bokito 17 cocoa agroforests; Zima 13; Ngomedzap 18). In each cocoa agroforest, a $1000-\mathrm{m}^{2}$ quadrat - representative of the whole plot in terms of technical management of the cocoa stand and associated tree communities - was set up in order to have a small sample of trees to monitor.

\subsection{Yield equation}

The marketable cocoa yield equation (yield) for a cocoa stand was formulated as follows: Yield $\left(\mathrm{kg} \mathrm{ha}^{-1}\right)=($ NbPods $\times$ Wbeans $\times \mathrm{TC}) \times$ KkoDens, where NbPods is the mean number of pods/cocoa tree, Wbeans is the mean weight of fresh beans/pod $(\mathrm{kg})$, TC is the marketable cocoa/fresh bean weight transformation coefficient, and KkoDens is the number of all cocoa trees/ha counted in the quadrat.

Wbeans depends on the number of beans/pod and the mean fresh bean weight which are two variables that in turn depend on the position of the pod in the tree (Lachenaud 1991). In order to avoid duplicating heavy observations already conducted by other researchers in cocoa agroforests similar to those in our monitoring network and located in the same study zones, we considered a constant mean fresh bean weight/pod of $0.115 \mathrm{~kg}$, i.e., a value obtained by Babin (2009). TC was also considered constant at 0.35 , i.e., a "conservative" value that is commonly used in hybrid cocoa tree comparative tests (Lachenaud 1984).

\subsection{Data collection and observed variables}

Our study focused on the cocoa yield variations between farmers' plots in a sample of 48 cocoa plots distributed in three zones. 
Cocoa yields per tree were calculated from the pod counts carried out over a 2-year period (2008-2009) in each quadrat, with three passages per year in June/July, August/September, and October/November. This frequency enabled us to account for the gradual emergence of pods after the onset of the rainy season, while also taking the gap between the southern (forest zones) and northern (forest-savannah transition zone) parts of central Cameroon into account. As pods smaller than $10-\mathrm{cm}$ long are susceptible to physiological wilt (Wood and Lass 2001), we only counted pods longer than $10 \mathrm{~cm}$, and we marked them to avoid double counts. These pod counts enabled us to calculate (i) the mean number of pods/cocoa tree (NbPods) and (ii) the number of unproductive adult cocoa trees (KkoUnp), which are the trees over 5 years old with an average productivity of less than two pods during the 2 years of follow-up.

Besides "Yield," "KkoUnp," and "NbPods," seven other variables were defined to characterize the structure and status of the cocoa stand and six other variables for the associated tree communities.

Cocoa stands were characterized by the following:

(i) KkoDens $\left(\mathrm{ha}^{-1}\right)$, the cocoa tree density measured by counting cocoa trees located in the $1000-\mathrm{m}^{2}$ quadrat.

(ii) KkoAge (years), the mean age of cocoa trees calculated on the basis of the age of each cocoa tree indicated by the farmer.

(iii) $\mathrm{KkoNbT}(\mathrm{n})$, the mean number of trunks per cocoa tree, which reflects cocoa stand rehabilitation practices under way in central Cameroon (Jagoret et al. 2011).

(iv) KkoBA $\left(\mathrm{cm}^{2}\right)$, the mean basal area per cocoa tree calculated on the basis of the diameters of each trunk per cocoa tree, measured $50 \mathrm{~cm}$ above the ground. This variable reflects the plant vigor of cocoa trees and is closely related to the productivity (Lachenaud and Mossu 1985).

(v) KkoTBA $\left(\mathrm{m}^{2} \mathrm{ha}^{-1}\right)$, the total basal area of the cocoa stand, calculated as the sum of the basal areas of all trees in the stand.

(vi) KkorelBA (\%), the relative basal area of the cocoa stand is the ratio of KkoTBA to the total basal area of all cocoa trees (KkoTBA) and associated trees (TRETBA) counted in the quadrat.

(vii) KkoHei (m), the mean height of cocoa tree crowns measured using a graduated gauge. This variable is an indicator of cocoa tree growth and varies according to the cropping and environmental conditions (Wood and Lass 2001).

The tree communities associated with cocoa trees were described through an inventory of all non-cocoa trees taller than 1-m height. The species identifications were based on vernacular names in the Yambassa language at Bokito, Eton language at Zima, and Ewondo language at Ngomedzap. Correspondences with the scientific names were established via the tree identification manual of Vivien and Faure (1985). Forest tree species were distinguished from fruit tree species such as Citrus sinensis, Persea americana, Mangifera indica, etc. (exotic species), and Elaeis guineensis, Dacryodes edulis, Cola nitida, Irvinguia gabonensis, Voaganga africana, and Garcinia kola (local species).

The tree communities associated with cocoa trees were characterized by the following:

(i) TREDens $\left(\mathrm{ha}^{-1}\right)$, the density of trees associated with cocoa trees per quadrat.

(ii) TRESpe (n), the number of species associated with cocoa trees per quadrat.

(iii) TRETBA $\left(\mathrm{m}^{2} \mathrm{ha}^{-1}\right)$, the total basal area of associated tree communities, calculated according to the sum of individual basal areas estimated on the basis of the diameter circumference of all individual tree trunks measured at breast height for adult trees (DBH), and at $0.5 \mathrm{~m}$ for juvenile trees.

(iv) TRErelBA (\%), the relative basal area of associated trees is the ratio of TRETBA to the total basal area of all cocoa trees and associated trees counted in the quadrat (KkoTBA + TRETBA).

(v) FRrelBA (\%), the relative basal area of fruit trees, is the ratio of their basal area to the total basal area of all cocoa trees and associated trees counted in the quadrat (KkoTBA + TRETBA).

(vi) FOrelBA (\%), the relative basal area of forest trees, is the ratio of their basal area to the total basal area of all cocoa trees and associated trees counted in the quadrat (KkoTBA + TRETBA).

\subsection{Statistical analysis}

An analysis of variance (ANOVA) was carried out to assess the effect of the different yield component factors or tree-type association (as explanatory variables) on cocoa yield as the dependent variable with farmers' cocoa plots and zones as replicates. Fisher's test was used for comparisons of means between the study zones. When significant differences between means were noted at $P<5 \%$, Newmann-Keuls test was used to compare means between zones. Correlation analysis was performed to segregate the most significant correlations between all variables. Then, a principal component analysis (PCA) was conducted to identify the main correlations between variables. Relationships between cocoa yield, its components and cocoa stand, and associated tree community structural variables were determined by multiple linear regressions with forward stepwise variable selection. Linear regression significance was assessed using Pearson's test (degree of 
freedom $=46$ ). All the statistical analyses were performed using XLSTAT (Addinsoft XLSTAT, version 2015).

\section{Results and discussion}

\subsection{Cocoa agroforestry systems productivity and features}

For all of the studied zones, the mean estimated cocoa yield was $737 \mathrm{~kg} \mathrm{ha}^{-1}$, with significant differences found between zones (Table 1A). This was higher than values usually obtained through surveys for cocoa agroforests in central Cameroon, i.e., $264 \mathrm{~kg} \mathrm{ha}^{-1}$ (Duguma et al. 2001), $255 \mathrm{~kg} \mathrm{ha}^{-1}$ (Jagoret et al. 2011), or elsewhere in Africa, i.e., $214 \mathrm{~kg} \mathrm{ha}^{-1}$ in Côte d'Ivoire and $454 \mathrm{~kg} \mathrm{ha}^{-1}$ in Ghana (Gockowski and Sonwa 2010). This would confirm the limits of surveys based on farmers' declarations. Indeed, it shows that assuming that these latter know exactly the quantities of cocoa they market but they often overestimate the area of their cocoa plots, thus leading to an underestimation of cocoa yields, when based on survey findings. Nevertheless, our results were in agreement with the yields estimated by Bisseleua et al. (2009) on the basis of pod counts, i.e., 897 to $2230 \mathrm{~kg} \mathrm{ha}^{-1}$ according to the cocoa stand intensification gradient.

We obtained a mean of 14 pods per cocoa tree, with significant differences noted between zones (Table 1A). These values were in line with those obtained by Marticou and Muller (1964) in the forest zone of central Cameroon where the authors observed a broad range of 13 to 46 pods per tree.

The mean density of cocoa stands was 1516 trees $^{-1}$, with significant differences observed between the surveyed areas (Table 1A). These values were in agreement with those obtained by Jagoret et al. (2011) with a different experimental design, i.e., 1280 trees ha $^{-1}$ (Bokito) to 1707 trees ha (Ngomedzap). They were also in line with the findings of Bisseleua and Vidal (2008) who, for the same zones, recorded 1075 to 1600 cocoa trees $\mathrm{ha}^{-1}$ according to a cocoa stand intensification gradient. These densities were also close to those recommended for simple cocoa cropping systems, i.e., 1330 to 1660 cocoa trees $\mathrm{ha}^{-1}$, under low interspecific competition (Wood and Lass 2001).

The mean basal area per cocoa tree was $61.6 \mathrm{~cm}^{2}$, while the mean total basal area of cocoa stands was $8.1 \mathrm{~m}^{2} \mathrm{ha}^{-1}$ with a mean relative basal area of $36.6 \%$. Significant differences
Table 1 Features $( \pm \mathrm{SD}$ of the mean) of cocoa agroforestry systems in central Cameroon (data measured in 48 plots, 2008-2009)

\begin{tabular}{|c|c|c|c|c|c|c|}
\hline \multirow[t]{2}{*}{ Variables } & \multirow[t]{2}{*}{$\mathrm{F}$} & \multirow[t]{2}{*}{$\mathrm{S}$} & \multicolumn{4}{|c|}{ Study zones } \\
\hline & & & Bokito & Zima & Ngomedzap & Mean $( \pm \mathrm{SD})$ \\
\hline \multicolumn{7}{|c|}{ A) Estimated cocoa yield and its components } \\
\hline Yield $\left(\mathrm{kg} \mathrm{ha}^{-1}\right)$ & 6.511 & $* *$ & $679 \mathrm{~b}$ & $1008 \mathrm{a}$ & $596 \mathrm{~b}$ & $737( \pm 52.06)$ \\
\hline NbPods $(n)$ & 4.179 & $*$ & $14 \mathrm{ab}$ & $20 \mathrm{a}$ & $10 \mathrm{~b}$ & $14( \pm 1.48)$ \\
\hline KKODens $\left(\mathrm{ha}^{-1}\right)$ & 4.449 & * & $1207 \mathrm{~b}$ & $1568 \mathrm{ab}$ & $1771 \mathrm{a}$ & $1516( \pm 87.15)$ \\
\hline \multicolumn{7}{|l|}{ B) Cocoa stands } \\
\hline $\operatorname{KKOBA}\left(\mathrm{cm}^{2}\right)$ & 5.079 & $* *$ & $70.9 \mathrm{a}$ & $72.8 \mathrm{a}$ & $44.7 \mathrm{~b}$ & $61.6( \pm 4.44)$ \\
\hline $\operatorname{KKOTBA}\left(\mathrm{m}^{2} \mathrm{ha}^{-1}\right)$ & 3.809 & $*$ & $8.1 \mathrm{a}$ & $9.9 \mathrm{a}$ & $6.9 \mathrm{~b}$ & $8.1( \pm 0.46)$ \\
\hline KKOrelBA $(\%)$ & 2.865 & * & $41.9 \mathrm{a}$ & $40.4 \mathrm{a}$ & $28.7 \mathrm{~b}$ & $36.6( \pm 2.73)$ \\
\hline KKOHei (m) & 8.487 & $* *$ & $2.9 \mathrm{~b}$ & $3.3 \mathrm{a}$ & $2.5 \mathrm{c}$ & $2.8( \pm 0.08)$ \\
\hline $\mathrm{KKONbT}(n)$ & 0.531 & Ns & $1.3 \mathrm{a}$ & $1.5 \mathrm{a}$ & $1.4 \mathrm{a}$ & $1.4( \pm 0.04)$ \\
\hline KKOAge (years) & 1.337 & Ns & $24 \mathrm{a}$ & $33 \mathrm{a}$ & $30 \mathrm{a}$ & $29( \pm 2.09)$ \\
\hline KKOUnp $(\%)$ & 5.758 & $* *$ & $17 \mathrm{~b}$ & $15 \mathrm{~b}$ & $30 \mathrm{a}$ & $21( \pm 2.32)$ \\
\hline \multicolumn{7}{|c|}{ C) Associated tree communities } \\
\hline TREDens $\left(\mathrm{ha}^{-1}\right)$ & 0.717 & $* *$ & $202 \mathrm{~b}$ & $155 \mathrm{a}$ & $205 \mathrm{~b}$ & $190( \pm 17.85)$ \\
\hline TRESpe (n) & 4.749 & $* *$ & $6.9 \mathrm{~b}$ & $8.1 \mathrm{~b}$ & $11.6 \mathrm{a}$ & $9.0( \pm 0.65)$ \\
\hline TRETBA $\left(\mathrm{m}^{2} \mathrm{ha}^{-1}\right)$ & 2.583 & $* *$ & $16.2 \mathrm{~b}$ & $16.2 \mathrm{~b}$ & $19.8 \mathrm{a}$ & $17.6( \pm 1.60)$ \\
\hline TRErelBA $(\%)$ & 3.609 & $* *$ & $57.6 \mathrm{~b}$ & $59.2 \mathrm{~b}$ & $71.1 \mathrm{a}$ & $63.3( \pm 2.79)$ \\
\hline FRrelBA (\%) & 4.505 & $* *$ & $39.7 \mathrm{a}$ & $21.4 \mathrm{~b}$ & $22.9 \mathrm{~b}$ & $28.5( \pm 2.99)$ \\
\hline FOrelBA (\%) & 8.370 & $* *$ & $17.8 \mathrm{~b}$ & $37.8 \mathrm{a}$ & $48.1 \mathrm{a}$ & $34.6( \pm 3.65)$ \\
\hline
\end{tabular}

Values within a line followed by the same letter are not significantly different $(P<0.01$, Newman-Keuls test) $\mathrm{NbPods}$ number of pods/cocoa tree, KKODens cocoa tree density, KKOBA mean basal area/cocoa tree, KKOTBA total basal area of the cocoa stand, KKOrelBA relative basal area of the cocoa stand, KKOHei mean height/cocoa tree, $K K O N b T$ mean number of trunks/cocoa tree, KKOAge mean cocoa tree age, KKOUnp unproductive adult cocoa trees, TREDens associated tree density, TRESpe number of species associated with cocoa trees, TRETBA total basal area of associated tree communities, TRErelBA relative basal area of associated stands, FRrelBA relative basal area of fruit trees, FOrelBA relative basal area of forest trees 
between zones were noted for these three variables (Table 1B). The basal area per cocoa tree was lower than the values reported by Bisseleua and Vidal (2008) for the same study zones, i.e., 71.6 to $199 \mathrm{~cm}^{2}$. It was also lower than other values reported in the literature, i.e., 69.5 to $317.9 \mathrm{~cm}^{2}$ (Lachenaud and Montagnon 2002), but these latter values were derived from comparative studies carried out in research stations on monocropped hybrids, whereas the plant material in cocoa agroforestry systems in central Cameroon is characterized by high genetic heterogeneity (Marticou and Muller 1964; Paulin et al. 2003). For a density of 1667 cocoa trees ha ${ }^{-1}$ (Lachenaud and Montagnon 2002), the total basal area of monocropped cocoa trees thus ranged from 11.5 to $52.9 \mathrm{~m}^{2} \mathrm{ha}^{-1}$ depending on the hybrid considered, which was therefore much higher than the levels noted in studied cocoa agroforests. The mean cocoa tree crown height was $2.8 \mathrm{~m}$, with significant differences noted between zones (Table 1B). This was within the range of 2.6 to 5.7 reported by Bisseleua and Vidal (2008) for the same zones. No significant differences were noted between zones regarding the number of trunks per cocoa tree and for the cocoa tree age (Table 1B). The mean unproductive adult cocoa tree rate was $21 \%$, with significant differences noted between zones (Table 1B).

The mean density of trees associated with cocoa was 190 trees $\mathrm{ha}^{-1}$, and significant differences were found between zones (Table 1C). This was similar to the values reported for Cameroon by Gockowski and Sonwa (2010), i.e., 120 to 256 trees ha ${ }^{-1}$, and by Bisseleua and Vidal (2008), i.e., 85 to 205 trees $\mathrm{ha}^{-1}$. However, they were much higher than those reported by Gockowski and Sonwa (2010) for Ghana (33 to 111), Nigeria (23), and Côte d'Ivoire (6 to 56), where cocoa trees are grown in less complex agroforestry systems than those in central Cameroon. Nine tree species, on average, were associated with cocoa trees, and significant differences were noted between zones (Table 1C). This value was not as high as those reported by Sonwa et al. (2007), i.e., 21 species, and by Bisseleua and Vidal (2008), i.e., 17 to 24 species. These variations could be explained by differences in the survey methodology adopted by these authors, i.e., the lower size of the quadrats in which they conducted their inventories and the thresholds of diameter at breast height they used to inventory the associated trees, i.e., less than $2.5 \mathrm{~cm}^{2}$ (Sonwa et al. 2007), or less than $10 \mathrm{~cm}^{2}$ (Bisseleua and Vidal 2008). The mean total basal area of associated trees was $17.6 \mathrm{~m}^{2} \mathrm{ha}^{-1}$ or $63.3 \%$ in terms of relative basal area (Table 1C). In the same areas, Bisseleua and Vidal (2008) obtained the total basal areas of associated trees ranging from 9 to $46 \mathrm{~m}^{2} \mathrm{ha}^{-1}$, depending on the cocoa stand intensification gradient. The mean relative basal area of fruit trees was $28.5 \%$, while that of forest trees was $34.6 \%$. Significant differences between zones were noted for these two variables (Table 1C).
Finally, our results confirmed that the three study sites differed greatly in terms of cocoa productivity and structural characteristics, both for cocoa stands and associated tree communities. These differences in structure appeared to be the result of both environmental conditions (forest zone vs forest-savannah transition zone) and management practices over time (Jagoret et al. 2017; Saj et al. 2017a).

\subsection{Relationships between the estimated cocoa yield, its components, and the cocoa agroforest structure}

\subsubsection{Relationship between cocoa yield and its components}

Considering all three zones, the estimated cocoa yield significantly increased with the mean number of pods per cocoa tree $(r=0.816 ; P<0.001)$. The same result was observed within each zone. The estimated cocoa yield was not, however, correlated with the cocoa tree density $(r=-0.186$; NS). Contrary to simple cocoa cropping systems (Lachenaud and Montagnon 2002), the cocoa tree density does not clearly explain the yields obtained in cocoa agroforests, as the competition of associated trees adds up to the more or less exacerbated competition between cocoa trees.

The mean number of pods per cocoa tree significantly decreased with the cocoa tree density $(r=-0.572 ; P<0.001)$. This negative correlation between the two yield components was confirmed intra-zone at $Z i m a ~(r=-0.704 ; P<0.001)$ and Ngomedzap $(r=-0.685 ; P<0.001)$. However, it was not significant at Bokito $(r=-0.280$; NS) likely because of the low variability of both variables in this zone. Indeed, at that site, the ratio between the minimum and maximum number of pods per cocoa tree was $1: 5$, whereas it was $1: 13$ at Ngomedzap and 1:29 at Zima. The ratio between the minimum and maximum cocoa tree density there was $1: 2.2$, as compared to 1:4 in the other zones.

\subsubsection{Factors that limit yield and yield components}

Regarding the PCA results, the first two axes explained 57.8\% of the observed variability (Fig. 2a). CPA axis 1 opposed cocoa tree vigor variables (mean, total, and relative basal area, height) to variables explaining yield gap, i.e., all variables characterizing strong associated tree communities (total density, total and relative basal area, relative basal area of forest tree species), cocoa tree density, and the unproductive adult cocoa tree rate. The number of pods (first yield component) being associated to cocoa tree vigor variables, axis 1 displayed, therefore, productivity and individualized the Ngomedzap study site from Zima and Bokito. CPA axis 2 concerned the status of cocoa trees in the system in terms of relative basal area compared to that of associated tree communities (total basal area and relative basal area of associated trees, relative basal area of forest trees). This axis segregated 
a Variables (axes F1 and F2: $\mathbf{5 7 . 8 8 \% )}$

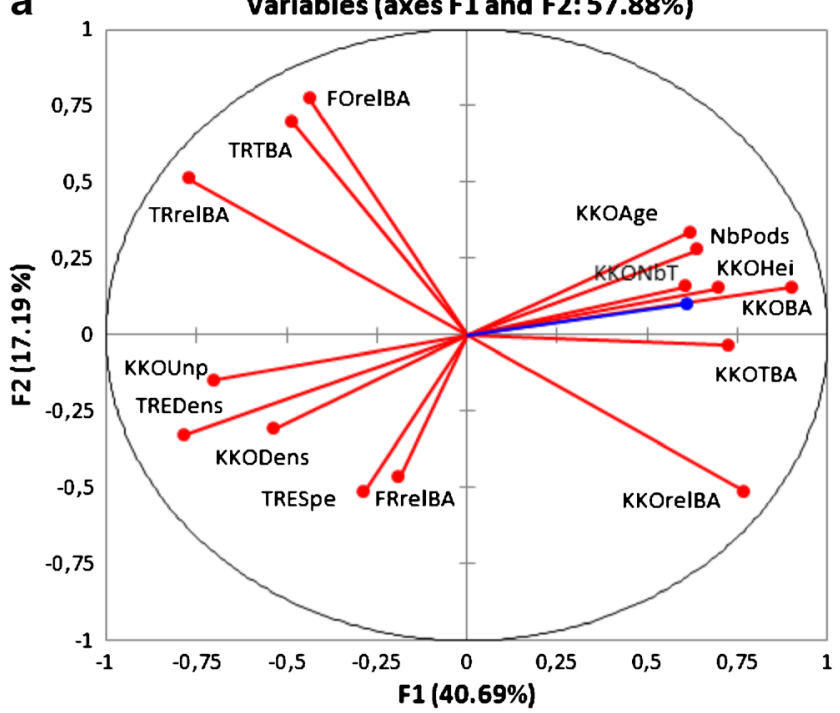

b

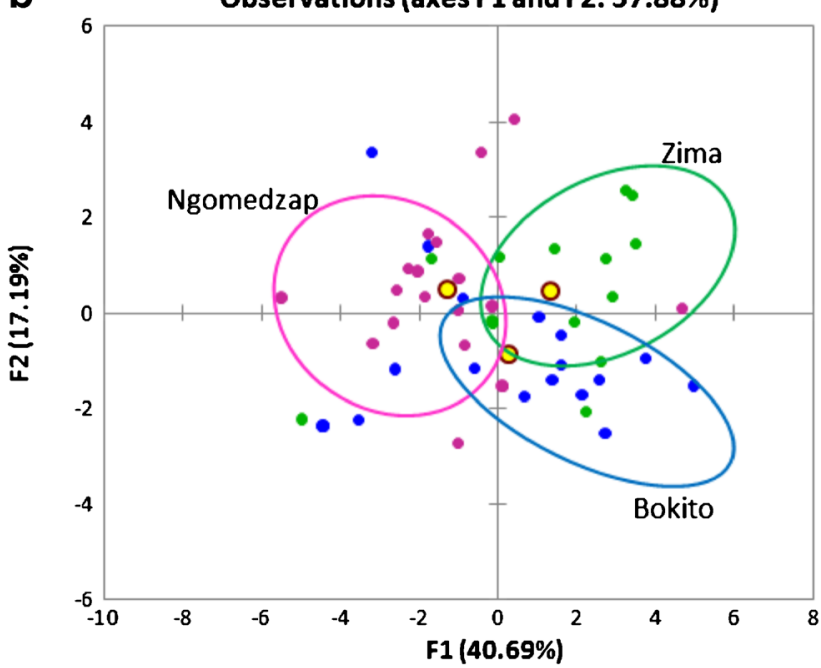

Fig. 2 a Principal component analysis with yield component variables, cocoa stand, and associated community structural variables. Yield (blue line) was projected as a supplementary variable. b Principal component analysis with yield component variables, cocoa stand, and associated community structural variables with the positions of the three study zones (all the plots from the three zones have been pooled)

also cocoa agroforests where forest trees were dominant from those where fruit trees are the majority in terms of relative basal area, and individualized the Bokito study site from both other zones. The cocoa agroforests representation in the PCA and the locations of the centers of gravity of the three sites revealed significant differences between the cocoa stands and the associated tree communities according to their structural features, their status, and their productivity (Fig. 2b). At a given associated tree density, the tree community compositions varied significantly between Ngomedzap (forest zone) and Bokito (forest-savannah transition zone). The cocoa agroforests structure in Ngomedzap was mainly dominated by forest trees whose footprint, in terms of total and relative basal area, was greater than in Bokito where cocoa agroforests were dominated by fruit trees (Table 1C). Meanwhile, Ngomedzap cocoa stands were significantly denser than at Bokito and Zima (Table 1A), but had a significantly smaller total and relative basal area than in these two zones (Table 1B). The same pattern was also noted for the mean basal area per cocoa tree, which was significantly lower at Ngomedzap, leading to a lower number of pods per cocoa tree (Table 1A).

Forward linear regression selected a model with three variables and with an explanatory power of $83.4 \%$ of the yield variability (Table $2 \mathrm{~A}$ ). In this model, the number of pods per cocoa tree and the cocoa tree density were deemed to be positively correlated with the estimated cocoa yield. In contrast, the unproductive adult cocoa tree rate was negatively correlated with the estimated cocoa yield.

The mean number of pods per cocoa tree was positively correlated with the mean basal area per cocoa tree (explanatory power of $46.5 \%$ of the variability) (Table 2B). The mean basal area per cocoa tree was positively correlated with the cocoa tree height and age (Table 2C), which reflects physiological relationship. Particularly, the cocoa tree productivity, basal area, and height were related and significantly increased with the cocoa tree age. Conversely, the mean basal area per cocoa tree was negatively correlated with the cocoa tree density which may indicate either intraspecific competition or the fact that farmers used to maintain high densities for young trees (Table 2C). Meanwhile, the mean basal area per cocoa tree was positively correlated with the relative basal area of the cocoa stand and with that of forest trees. This may indicate that intraspecific and interspecific competitions were reduced in the agroforests where the densities of cocoa trees and those of forest trees were low and in line with the growth of cocoa trees which can therefore occupy more space in terms of total basal area.

The unproductive cocoa tree rate was positively correlated with the cocoa tree density and with two structural variables of the associated tree communities, i.e., the associated tree density and the fruit trees relative basal area (Table 2D). Conversely, it was negatively correlated with the number of species associated with cocoa trees. These different correlations suggest two methods to increase cocoa yields: (i) to opt for relatively low density of both cocoa and associated trees and (ii) to limit the number of species associated with cocoa trees.

These overall results showed that the mean basal area per cocoa tree and the rate of unproductive adult cocoa tree are two key factors to assess the productivity of the studied cocoa agroforestry systems. The correlation between the basal area per cocoa tree and the mean number of pods per cocoa tree confirmed the close relationship between cocoa tree productivity and vigor (Lachenaud and Mossu 1985). The negative correlation between the mean basal area per cocoa tree and the cocoa tree density could be explained by the intraspecific competition due to farmers' ongoing redensification practices 
Table 2 Regression statistics for yield, pod number, average cocoa basal area and percentage of unproductive cocoa, with variables listed in order of selection using a step forward procedure (data measured in 48 plots, 2008-2009)

\begin{tabular}{lrlrll}
\hline Significant variables & Estimate & Standard error & \multicolumn{1}{l}{$T$} & $P>|t|$ & Cumulative $r^{2}$ \\
\hline A) Yield & & & & & \\
NbPods & 31.091 & 1.688 & 18.417 & $<0.0001$ & 0.387 \\
KKODens & 2.995 & 0.345 & 8.684 & $<0.0001$ & 0.771 \\
KKOUnp & -7.438 & 1.801 & -4.129 & 0.001 & 0.834 \\
B) NbPods & & & & & \\
KKOBA & 0.232 & 0.016 & 14.698 & $<0.0001$ & 0.465 \\
C) KKOBA & & & & & \\
KKOHei & 15.953 & 3.076 & 5.187 & $<0.0001$ & 0.362 \\
KKODens & -0.222 & 0.034 & -6.533 & $<0.0001$ & 0.606 \\
KKOrelBA & 0.811 & 0.145 & 5.602 & $<0.0001$ & 0.740 \\
FOrelBA & 0.245 & 0.102 & 2.393 & 0.021 & 0.781 \\
KKOAge & 0.368 & 0.179 & 2.054 & 0.046 & 0.800 \\
D) KKOUnp & & & & & \\
KKODens & 0.107 & 0.020 & 5.315 & $<0.0001$ & 0.363 \\
TREDens & 0.787 & 0.150 & 5.256 & $<0.0001$ & 0.494 \\
TRESpe & -7.269 & 1.582 & -4.596 & $<0.0001$ & 0.603 \\
FRrelBA & 0.207 & 0.077 & 2.680 & 0.01 & 0.658 \\
\hline
\end{tabular}

NbPods number of pods/cocoa tree, KKODens cocoa tree density, KKOUnp unproductive adult cocoa trees, KKOBA mean basal area/cocoa tree, KKOHei mean cocoa tree height, KKOrelBA relative basal area of the cocoa stand, KKOAge mean cocoa tree age, TREDens associated tree density, TRESpe number of species associated with cocoa trees, FRrelBA relative basal area of fruit trees
(Jagoret et al. 2011). These practices were geared towards systematic cocoa tree replanting in order to maintain a constant stand density over time, thus hampering their vegetative growth. Regarding monospecies cocoa stands where the initial densities were close to those in our studied agroforestry systems, the decrease in cocoa tree density over time, due to the lack of replacement of trees that had disappeared (Bastide et al. 2008) or caused by rationally managed clearing (Lachenaud and Montagnon 2002), actually reduced competition while having a positive impact on the productivity of the remaining cocoa trees. However, in the case of cocoa agroforests in central Cameroon, a reduction in cocoa tree density did not always lead to an increase in their productivity because the different tree communities associated with cocoa trees maintained a competition between cocoa trees and others species. There was a positive correlation between the density of cocoa and density of associated trees $(r=0.527 ; P<0.001)$, which thus made it difficult to differentiate intra- and interspecific competition within the cocoa agroforestry systems.

Resource-sharing competition from forest trees was reflected by the lower mean basal area per cocoa tree and consequently lower cocoa yields. These results confirmed those reported by Besse (1972) who, in Côte d'Ivoire, showed that the removal of shade tree led to a $253 \%$ increase in the mean cocoa yield per tree over a 5-year period. Similarly, Lachenaud and Mossu (1985) showed that the yield of monocropped cocoa trees was $247 \%$ higher than that of a cocoa agroforest because of the greater cocoa tree vigor, more abundant flowering, and reduced physiological wilt, likely due to the better lighting conditions, leading to enhanced photosynthesis. The observations done by Koko et al. (2013) in an on-farm trial in Côte d'Ivoire have shown that vigor and cocoa yields were very highly correlated with the incident light received by cocoa trees. These latter yielded 30.3 pods tree $^{-1}$ when combined with orange trees and 28.3 pods tree ${ }^{-1}$ with avocado trees, instead of 64 pods tree year $^{-1}$ in the monocrop. Both the cocoa yield and the incident light were a logistic function of the planting distance from the shade trees. Our results were also in line with those of Blaser et al. (2017) who, in Ghana, showed that cocoa growth was lower under shade trees and decreased with increasing shade-tree cover, as it was also observed for cocoa yield.

The correlation between the unproductive adult cocoa tree rate on one hand, and the density of associated trees or the number of associated species on the other hand (Table 2D) confirmed that competition for water, light, and nutrients was a factor limiting yield build-up in cocoa stands (Besse 1972; Lachenaud and Mossu 1985). However, this effect was less marked with fruit trees, indicating that cocoa with fruit tree associations could limit interspecific competition within agroforestry systems. This was the case in the Bokito zone where the relative basal area of fruit trees was significantly higher than in the Ngomedzap forest zone for a significantly lower unproductive adult cocoa tree rate (Table 1B). In this forestsavannah transition zone, Jagoret et al. (2012) showed that not only cocoa agroforestry systems were dominated by fruit 
tree species, but also that their long-term management by farmers, as was the case with forest tree species, was geared towards reducing interspecific competition via the elimination of excess individuals. In young cocoa stands, however, trees associated with cocoa trees were voluntarily planted at high density to quickly obtain dense ground cover to hamper weed growth, and provide suitable shade for the cocoa trees. Then, their density subsequently declined significantly over 40 years from 223 to 44 trees $^{-1} a^{-1}$ for fruit trees and from 68 to 27 trees $\mathrm{ha}^{-1}$ for forest trees.

Our results showed also that cocoa trees can be grown in complex agroforestry systems while obtaining higher yields than those usually mentioned for agroforestry systems. The mean cocoa yield observed in Zima, higher than $1 \mathrm{t} \mathrm{ha}^{-1}$ (Table 1A), was obtained in agroforests where cocoa trees were grown with eight associated species at a density of 155 trees $\mathrm{ha}^{-1}$. In these cocoa agroforests, cocoa trees represented a relative basal area of $40 \%$, while relative basal areas of forest trees and fruit trees were roughly of 40 and $20 \%$, respectively. These results confirmed that trade-offs between cocoa tree density and associated tree density are possible to support a good level in cocoa production. They were in line with those obtained by Saj et al. (2017a) who found that very long-term sustainability could be achieved if the relative basal area of cocoa trees does not exceed $40 \%$. These authors found also that some associated functional groups of woody species were consistently related to higher cocoa yield, highlighting that, in some cases, putative synergistic, or less damageable, effects on cocoa yields are successfully obtained by farmers. Finally, our results, and those of Saj et al. (2017b) who showed that cocoa agroforestry systems of central Cameroon are able to combine high levels of species richness with long-term conservation abilities and carbon storage, confirmed that tradeoffs between cocoa yield and the growing of many species that contribute to the functioning of households (Cerda et al. 2014; Jagoret et al. 2014a) are possible.

\subsection{General framework to assess complex cocoa agroforestry systems}

\subsubsection{Revision of the cocoa yield equation}

Our study revealed that the agroforestry systems included a significant number of unproductive adult cocoa trees, which is seldom the case in monospecies cocoa plantations and in experimental plots. The unproductive cocoa tree rate was of $30 \%$ in the Ngomezap zone (Table 1B). The very highly significant positive relationship between the pod number per cocoa tree (NbPods) and the mean basal area per cocoa tree (KkoBA) (Table 2B) showed that, for each zone, it was possible to estimate $\mathrm{NbPods}$ through the equation $\mathrm{NbPods}=a \times \mathrm{KkoBA}+b$, where $a$ and $b$ were calculated on the basis of the regression curves for each zone. Based on our results, the equation parameters are $a=0.290$ and $b=0.011$. As the regression line was highly significant ( $r=0.766 ; P<0.001)$, it was thus possible to estimate the number of pods through the calculated formula. The regression lines enabled us to develop an NbPods estimation model including the yield equation. The equation between the number of counted and estimated pods was NbPods real $=0.899 \times \mathrm{NbPods}$ calculated. The relationship was significant for all three zones $(r=0.602 ; P<0.001)$.

Moreover, as unproductive adult cocoa trees (KkoUnp) are those producing less than two pods, this threshold enables us to determine the mean basal area of unproductive cocoa trees from the regression lines. In practice, the equation of Fig. 3 gives $X=19 \mathrm{~cm}^{2}$ for $Y=2$. Thus, instead of the total cocoa tree density (KkoDens), in the yield equation, it is now possible to reformulate the yield equation in function of the actual number of productive cocoa trees (KkoProd), which is calculated by the difference between two parameters easily measurable in the field: KkoProd $=$ KkoDens - KkoUnp, where KkoUnp is the number of cocoa trees with a total basal area of less than $19 \mathrm{~cm}^{2}$ (diameter of $5 \mathrm{~cm}$ ). The yield of studied cocoa agroforests could therefore be estimated by the following equation: Yields $=(a \times \mathrm{KkoBA}+$ b) $\times($ KkoDens - KkoUnp) $\times$ WBeans $\times$ TC; where (i) $a$ and $b$ were obtained through a NbPods linear regression analysis based on KkoBA; i.e., $a=0.295$ and $b=-0.341$, and (ii) (KkoDens - KkoUnp) was the number of productive cocoa trees, given that KkoUnp = (sum of cocoa trees having a KkoBA $<19 \mathrm{~cm}^{2}$ ). In cocoa agroforestry systems, the yield can thus be estimated with only two parameters, which in turn are the result of other yield components, as shown in Table 1.

Although the density of associated trees and their type (forest or fruit trees) seem to be key factors in the functioning of cocoa agroforestry systems, our results showed that the rate of

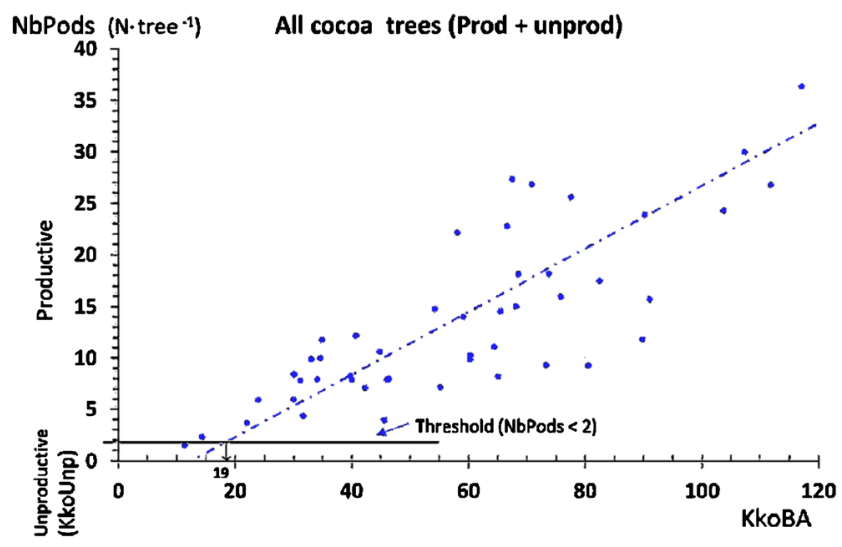

Fig. 3 Relationship of NbPods (number of pods/cocoa tree) to KkoBA (mean basal area/cocoa tree) showing the threshold used to separate unproductive cocoa trees $(\mathrm{NbPods}<2)$ from productive trees (all the plots from the three zones have been pooled). The regression analysis shows that cocoa yields are highly significantly correlated with cocoa basal area. When the number of pods $(y)=0$, the basal area $(x 0)$ is the threshold under which cocoa trees can be considered as unproductive; e.g., in this trial, $\mathrm{x} 0$ is $19 \mathrm{~cm}^{2}$ 
the unproductive cocoa trees-which reflected the cropping practices adopted by farmers - was also an important variable to assess the cocoa yields in agroforestry systems. This is in favor of the elimination of unproductive cocoa trees $\left(\mathrm{KkoBA}<19 \mathrm{~cm}^{2}\right)$ to enable the other ones to develop their basal areas.

\subsubsection{Adaptation of the regional agronomic diagnosis method}

Complex cacao agroforestry systems are the result of farmers' decisions on decades to design a specific field structure characterized by plant population density, basal area, and age of several ligneous species, including cocoa stands which are the main component of these systems managed by farmers to produce cocoa (Jagoret et al. 2011). In order to identify the main causes of cocoa yield variations, the assessment of these systems in central Cameroon allowed us not to consider the annual crop practices in our analysis but instead to integrate tree management practices that make sense in relation to the structure of the systems; i.e., implementation and long-term management practices. These practices differ from annual crop management practices (soil maintenance, crop protection treatments). They are carried out periodically and individually (tree by tree) by farmers based on their field observations, but have a medium- to long-term impact on the system structure, and thus on cocoa yields (Jagoret et al. 2017).

As cocoa agroforests are regularly weeded, we assume that the role of weeds in terms of interspecific competitions is less important than that of woody species. Insect and disease injuries were not observed because these factors will require further heavy studies to see how the structure of the studied agroforestry systems may influence the presence of bioagressors, particularly the mirids and black pod disease, and their impact on cocoa yield. To overcome this difficulty, we decided to estimate the accessible cocoa yield by counting pods longer than $10 \mathrm{~cm}$, assuming that they will reach maturity and will be harvested by farmers.

In this paper, we considered soil and climatic conditions as homogeneous within each region. In central Cameroon, soil and climatic conditions are considered to satisfy the ecological requirements of cocoa trees (Wood and Lass 2001). In addition, we assumed that characteristics of the cocoa agroforests structure may reflect soil and climatic conditions: for instance, the number of forest tree species is higher in the area of Ngomedzap (located in the humid forest zone) than in Bokito (located in a drier forest-savanna transition zone) (Jagoret et al. 2011). Characteristics of the cocoa agroforests such as the type and uses of associated species also depend from local farmer's decisions: for instance, the use of fruit species in cocoa agroforests in Bokito is not the same than in Ngomedzap (Jagoret et al. 2014a).

To overcome the short time by not considering its annual management of these agroforestry systems also has the advantage of providing access to relevant indicators and easily measured variables at time $t$ (density, basal area, species composition, etc.) to characterize stands while accounting for their heterogeneity, which is the main barrier to overcome when assessing complex systems (Doré et al. 2008).

Our approach - considering associated tree communities as an environmental component (like soil and climate) with regard to the cocoa stand - enabled us to incorporate the system structure into the analytical framework of relationships between practices, environmental status, and that of the cultivated stand and performances that are generally considered in the analysis of annual crop-based cropping systems (Doré et al. 1997. Our approach also enabled us to adapt the cropping system concept as defined by Doré et al. (1997). In annual crop-based monoculture systems, interactions between technical practices over time primarily occur via the soil (previous or cumulative effects). However, in the complex agroforestry systems that prevail in the humid tropics, in the absence of crop rotations, stands are planted and maintained for several decades, and each tree develops separately over time according to farmers' practices. Interactions between technical practices therefore do not solely occur via the soil but also, and especially, via the status of the different stands that farmers can modify by altering their structure.

\section{Conclusion}

This study was the first attempt to apply the regional agronomic diagnosis method to assess cocoa yields in complex agroforestry systems. Our findings confirmed that the basal area per cocoa tree and the unproductive adult cocoa tree rate are key factors to assess the productive performance of cocoa agroforestry systems. We confirmed that cocoa trees could be grown and be productive in such systems, although they are opposite to the intensive system usually advised to cocoa farmers. Actual cocoa yields were higher than those usually mentioned for agroforestry systems, suggesting that trade-offs in the management of cocoa trees and associated species are possible. From a methodological standpoint, by tailoring the regional agronomic diagnosis method, we were able to overcome the specific obstacles linked with the features of agroforestry systems, especially their complexity and their heterogeneity. We succeeded to use this method to assess cocoa yields in complex agroforestry systems relative to their structure as an essential component of the cropping system and thus identify the main causes of cocoa yield variations. Indeed, the productivity of the system cannot be focused solely on the cocoa yield since the associated fruit and forest trees are also productive, and the method should of course be tailored to the different species present in order to obtain an overall assessment of the productivity of these systems. Finally, we believe that these systems are therefore a source 
of inspiration to design more ecologically efficient cocoa cropping systems to cope with current challenges facing world cocoa production.

Funding This study was carried out in partnership with the Institut de Recherche Agricole pour le Développement (IRAD, Cameroon) and the Centre de coopération Internationale en Recherche Agronomique pour le Développement (CIRAD, France) in the framework of the Research and Training Platform in Partnership "Agroforestry Cameroon," and the project, "Strengthening agricultural research partnerships in Cameroon," funded by the French Ministry of Foreign Affairs.

Open Access This article is distributed under the terms of the Creative Commons Attribution 4.0 International License (http:// creativecommons.org/licenses/by/4.0/), which permits unrestricted use, distribution, and reproduction in any medium, provided you give appropriate credit to the original author(s) and the source, provide a link to the Creative Commons license, and indicate if changes were made.

\section{References}

Altieri MA, Rosset PM (1995) Agroecology and the conversion of largescale conventional systems to sustainable management. Int J Env Stud 50:165-185. https://doi.org/10.1080/00207239608711055

Babin R (2009) Contribution à l'amélioration de la lutte contre le miride du cacaoyer Sahlbergella singularis Hagl. (Hemiptera : Miridae). Influence des facteurs agro-écologiques sur la dynamique des populations du ravageur. Thèse de doctorat, Université Montpellier IIIPaul Valéry. Montpellier, France, p. 202

Bastide P, Paulin D, Lachenaud P (2008) Influence de la mortalité des cacaoyers sur la stabilité de la production dans une plantation industrielle. Tropicultura 26:33-38

Besse J (1972) Comparaison de deux méthodes d'établissement de cacaoyères. Café Cacao Thé 16:317-331

Bisseleua DH, Vidal BS (2008) Plant biodiversity and vegetation structure in traditional cocoa forest gardens in southern Cameroon under different management. Biodivers Conserv 17:1821-1835. https:// doi.org/10.1007/s10531-007-9276-1

Bisseleua DH, Missoup AD, Vidal BS (2009) Biodiversity conservation, ecosystem functioning, and economic incentives under cocoa agroforestry intensification. Conserv Biol 23(5):1176-1184. https://doi. org/10.1111/j.1523-1739.2009.01220.x.

Blaser WJ, Oppong J, Yeboah E, Six J (2017) Shade trees have limited benefits fir soil fertility in cocoa agroforests. Agric Ecosyst Environ 243:83-91. https://doi.org/10.1016/j.agee.2017.04.007

Cerda R, Deheuvels O, Calvache D, Niehaus L, Saenz Y, Kent J, Vilchez S, Villota A, Martinez C, Somarriba E (2014) Contribution of cocoa agroforestry systems to family income and domestic consumption: looking toward intensification. Agrofor Syst 88:957-981. https:// doi.org/10.1007/s10457-014-9691-8

Clough Y, Faust H, Tscharntke T (2009) Cacao boom and bust: sustainability of agroforests and opportunities for biodiversity conservation. Conserv Lett 2:197-205. https://doi.org/10.1111/j.1755263X.2009.00072.x

Doré T, Sebillotte M, Meynard JM (1997) A diagnostic method for assessing regional variations in crop yield. Agric Syst 54:169-188. https://doi.org/10.1016/S0308-521X(96)00084-4

Doré T, Clermont-Dauphin C, Crozat Y, David C, Jeuffroy MH, Loyce C, Makowski D, Malézieux E, Meynard JM, Valantin-Morison M (2008) Methodological progress in on-farm regional agronomic diagnosis: a review. Agro Sustain Dev 28:151-161. https://doi.org/10. 1007/978-90-481-2666-8-45.
Duguma B, Gockowski J, Bakala J (2001) Smallholder cacao (Theobroma cacao Linn.) cultivation in agroforestry systems of West and Central Africa: challenges and opportunities. Agrofor Syst 51:177-188. https://doi.org/10.1023/A:1010747224249.

Gaba S, Lescourret F, Boudsocq S, Enjalbert J, Hinsinger P, Journet EP, Navas ML, Wery J, Louarn G, Malézieux E, Pelzer E, Prudent M, Ozier-Lafontaine H (2015) Multiple cropping systems as drivers for providing multiple ecosystems services: from concept to design. Agro Sustain Dev 35(2):607-623. https://doi.org/10.1007/s13593014-0272-z

Gockowski J, Sonwa D (2010) Cocoa intensification scenarios and their predicted impact on $\mathrm{CO}_{2}$ emissions, biodiversity conservation, and rural livelihoods in the Guinea rainforest of West Africa. Environ Manag 48(2):307-321. https://doi.org/10.1007/s00267-010-9602-3

ICCO (2016) Annual report 2011-2012, London

Jagoret P, Bouambi E, Menimo T, Domkam I, Batomen F (2008) Analyse de la diversité des systèmes de pratiques en cacaoculture : cas du Centre Cameroun. Biotechnol Agron Soc Environ 12(4):367-377

Jagoret P, Michel-Dounias I, Malezieux E (2011) Long-term dynamics of cocoa agroforests: a case study in central Cameroon. Agrofor Syst 81(3):267-278. https://doi.org/10.1007/s10457-010-9368-x

Jagoret P, Michel-Dounias I, Snoeck D, Todem Ngnogué H, Malézieux E (2012) Afforestation of savannah with cocoa agroforestry systems: a small-farmer innovation in central Cameroon. Agrofor Syst 86:493-504. https://doi.org/10.1007/s10457-0129513-9

Jagoret P, Kwesseu J, Messie C, Michel-Dounias I, Malézieux E (2014a) Farmers' assessment of the use value of agrobiodiversity in complex cocoa agroforestry systems in central Cameroon. Agrofor Syst 88(6):983-1000. https://doi.org/10.1007/s10457-014-9698-1

Jagoret P, Deheuvels O, Bastide P (2014b) Sustainable cocoa production. Learning from agroforestry. Perspective ${ }^{\circ} 27$. Cirad, Montpellier

Jagoret P, Snoeck D, Bouambi E, Todem Ngnogue H, Nyassé S, Saj S (2017) Rehabilitation practices that shape cocoa agroforestry systems in Central Cameroon: key management strategies for long-term exploitation. Agrofor Syst (on line). https://doi.org/10.1007/s10457016-0055-4

Koko LK, Snoeck D, Lekadou TT, Assiri LA (2013) Cacao-fruit tree intercropping effects on cocoa yield, plant vigour and light interception in Côte d'Ivoire. Agrofor Syst 87:1043-1052. https://doi.org/ 10.1007/s10457-013-9619-8

Lachenaud P (1984) Une méthode d'évaluation de la production de fèves fraîches applicable aux essais entièrement randomisés. Café Cacao Thé 28:21-30

Lachenaud P, Mossu G (1985) Etude comparative de l'influence de deux modes de conduite sur les facteurs du rendement d'une cacaoyère. Café Cacao Thé 29:21-30

Lachenaud P (1991) Facteurs de la fructification chez le cacaoyer (Theobroma cacao L.). Influence sur le nombre de graines par fruit. Thèse de doctorat, Institut national agronomique Paris-Grignon. Paris, France, p. 188

Lachenaud P, Montagnon C (2002) Competition effects in cocoa (Theobroma cacao L.) hybrid trials. Euphytica 128:97-104. https://doi.org/10.1023/A:1020669526647.

Leterme P, Manichon H, Roger-Estrade J (1994) Analyse intégrée des rendements de blé tendre et de leurs causes de variation dans un réseau de parcelles d'agriculteurs du Thymerais. Agronomie 14: 341-361

Malézieux E, Crozat Y, Dupraz C, Laurans M, Makowski D, OzierLafontaine H, Rapidel B, de Tourdonnet S, Valantin-Morison M (2008) Mixing plant species in cropping systems: concepts, tools and models: a review. Agron Sustain Dev 29:43-62. https://doi. org/10.1007/978-90-481-2666-8-22

Malézieux E (2012) Designing cropping systems from nature. Agron Sustain Dev 32:15-29. https://doi.org/10.1007/s13593-011-0027-z 
Marticou H, Muller R (1964) Essai de mise au point d'une méthode d'expérimentation adaptée aux conditions de la cacaoyère camerounaise traditionnelle. Café Cacao Thé 8:173-201

Michels T (2005) Adapter la conduite des plantations d'hévéa à la diversité des exploitations villageoises (Etude de cas au Cameroun). Thèse de doctorat, Institut national agronomique Paris-Grignon, Paris, France, p 245

Metral R, Wery J (2001) Evaluation of limiting factors of food legumes yields in farmer's field: development of a diagnosis methology and first results in three french regions. In: $4^{\text {th }}$ European conference on grain legumes, July 8-12th 2001, Cracovie. Paris, Aep : 48-49.

Paulin D, Snoeck L, Nyassé S (2003) Survey on the growing practices and planting material used for cocoa growing in the central region of Cameroon. Ingenic Newsletter 8:5-8

Rafflegeau S, Michel-Dounias I, Taillez B, Ndigui B, Papy F (2010) Unexpected $\mathrm{N}$ and $\mathrm{K}$ nutrition diagnosis in oil palm smallholdings using references of high-yielding industrial plantations. Agron Sustain Dev 30:777-787. https://doi.org/10.1051/agro/2010019

Rafflegeau S, Losch B, Daviron B, Bastide P, Charmetant P, Lescot T, Prades A, Sainte Beuve J (2014) Chapitre 7. Contribuer à la production et aux marchés internationaux. Pp 129-143. JM Sourisseau (Ed). Agricultures familiales et mondes à venir. Quae, Versailles. ISBN 978-2-7529-2141-7

Santoir C, Bopda A (1995) Atlas régional Sud-Cameroun. Orstom, Paris ISBN 2-7099-1271-6
Saj S, Jagoret P, Etoa LE, Eteckji Fonkeng E, Tarla JN, Essobo Nieboukaho J-D, Mvondo Sakouma K (2017a) Lessons learned from the long-term analysis of cacao yield and stand structure in central Cameroonian agroforestry systems. Agric Syst 156:95104. https://doi.org/10.1016/j.agsy.2017.06.002

Saj S, Durot C, Mvondo Sakouma K, Tayo Gamo K, Avana-Tientcheu M-L (2017b) Contribution of associated trees to long-term species conservation, carbon storage and sustainability: a functional analysis of tree communities in cacao plantations of Central Cameroon. Int $\mathbf{J}$ Agric Sustain 15(3):282-302. https://doi.org/10.1080/14735903. 2017.1311764

Scopel E, Louette D (1992) Une méthode de diagnostic agronomique basée sur l'enquête : application au maïs pluvial à Pueblo-Juarez, Mexique. L'agronomie tropicale 46:283-294

Sonwa DJ, Nkongmeneck AB, Weise SF, Tchatat M, Adesina AA, Janssens MJ (2007) Diversity of plants in cocoa agroforests in the humid forest zone of Southern Cameroon. Biodivers Conserv 16: 2385-2400. https://doi.org/10.1007/s10531-007-9187-1

Tilman D, Cassman K, Matson P, Naylor R, Polasky S (2002) Agricultural sustainability and intensive production practices. Nature 418:674-677. https://doi.org/10.1038/nature01014

Vivien J, Faure JJ (1985) Arbres des forêts denses d'Afrique centrale. Agence de coopération culturelle et technique, Paris ISBN 2-11$084796-4$

Wood GAR, Lass RA (2001) Cocoa, Fourth edn. Wiley-Blackwell, London ISBN 978-0-632-06398-7 